\title{
Social Responsibility of Organizational Management
}

\author{
Nasser Fegh-hi Farahmand \\ Department of Industrial Management, Tabriz Branch, Islamic Azad University, Tabriz, Iran
}

\begin{abstract}
Social Responsibility of Organizational Management is the responsibility of every manager. Because, Organizational Social Responsibility (OSR) functions as a built-in, self-regulating mechanism whereby business monitors and ensures its active compliance with the spirit of the law, ethical standards, and international norms. An approach for OSR that is becoming more widely accepted is a community-based development approach. In Organizational Social Responsibility Approach (OSRA), corporations work with local communities to better themselves. In addition, Managerial Social Responsibility (MSR) is the responsibility of every manager for his/her actions. It is morally binding on everyone to act in such a way that the people immediately around them are not adversely affected.For this reason, Organizational Social Responsibility Policy (OSRP) functions as a built-in, self-regulating mechanism.
\end{abstract}

Keywords Managerial Social Responsibility, Organizational Social Responsibility, Corporate Social Responsibility

\section{Introduction}

Organizational Social Responsibility Policy (OSRP) functions as a built-in, self-regulating mechanism whereby business monitors and ensures its active compliance with the spirit of the law, ethical standards, and international norms. The goal of OSRP is to embrace responsibility for the company's actions and encourage a positive impact through its activities on the environment, consumers, employees, communities, stakeholders and all other members of the public sphere.

The goal of OSRP is to embrace responsibility for the company's actions and encourage a positive impact through its activities on the environment, consumers, employees, communities, stakeholders and all other members of the public sphere.

Furthermore, OSRP focused businesses would proactively promote the public interest by encouraging community growth and development, and voluntarily eliminating practices that harm the public sphere, regardless of legality. OSR is the deliberate inclusion of public interest into corporate decision-making that is the core business of the company or firm, and the honoring of a triple bottom line: people, planet, profit.

\section{Managerial Social Responsibility}

Mintzberg followed five top managers (Feghhi Farahmand, 2005, 273) for one week each and even though they

* Corresponding author:

farahmand@iaut.ac.ir (Nasser Fegh-hi Farahmand)

Published online at http://journal.sapub.org/mm

Copyright (C) 2011 Scientific \& Academic Publishing. All Rights Reserved supposedly deal with big questions, he reports that half of the activities they engaged in lasted less than nine minutes (Feghhi Farahmand, 2004, 417).

It is instructive to reproduce some examples of decisions made by the top managers (Mintzberg, 1973, 242):

1) Is organization worth spending resources looking into new equipment?

2) Does organization allow a specific exception from an operating procedure?

3) What is organization position on a fee for rework done by a supplier?

4) How does organization react to a solicitation from our trade association?

5) Should organization adopt a new operating procedure?

6) Will organization grant a client's wish for a change in work done?

7) Should organization contribute to a charitable organization?

Individually, each of these decisions took very little time, but there were a lot of them and they all had to make. For example, in and outgoing mail provides another angle on the constant demands for managerial social responsibility attention, on the average, the men were asked to process few pieces of mail per day, but they themselves initiated only one piece per day.

The bulk of managerial social responsibility consists in reacting to external and organizational events, rather than planning grand strategies and consistent with this, most of the social responsibilities initiated by others. They often arrived at unpredictable times. One of the jobs of the top managers is simply to be around such that the organization can react to unanticipated developments as they take place.

In organizations, the top managers do not even make all the decisions and many decision rights delegated to lower level employees, and the top managers do not participate at 
all presumably because it is too costly to involve him (Feghhi Farahmand, 2004, 311).

\section{Social Responsibility Strategy}

Social Responsibility analysis is a planning exercise in which managers identify organizational strengths (S) and weaknesses (W), and environmental opportunities (O) and Threats (T). Social Responsibility by SWOT analysis should not only result in the identification of a corporation's distinctive competencies, but also in the identification of opportunities that the firm is not currently able to take advantage of; due to lack of appropriate resources.

By having each or all of the four strategic factors namely SWOT, handy for any strategic decision making or a successful activity somehow, still there is a need for a final efficient factor, which could make any of the four known elements effective.

These processes require a deep right, authority and analysis about the helping factors outside the known four elements. In this argument, organization introduces social responsibility rights as supportive elements.

As a critique on social responsibility strategy and the factors which shape it, this research is going to describe the need and necessity of supportive elements from which every strategy more, or less may in one or the other way take advantage (Feghhi Farahmand, Nasser, 2003, 409).

\section{Organizational Social Responsibility Approach}

An approach for OSR that is becoming more widely accepted is a community-based development approach. In Organizational Social Responsibility Approach (OSRA), corporations work with local communities to better themselves. A more common approach of OSR is philanthropy as follows:

a) Monetary donations, aid given to organizations and impoverished communities in developing. Some organizations do not like this approach as it does not help build on the skills of the local people, whereas community-based development generally leads to more sustainable development.

b) Incorporate the OSR strategy directly into the business strategy of an organization.

c) Increase of interest for corporate responsibility. This called creating shared value.

An organization needs a healthy, educated workforce, sustainable resources and adept government to compete effectively. For society to thrive, profitable and competitive businesses must develop and supported to create income, wealth, tax revenues, and opportunities for philanthropy.

Many approaches to OSR pit organization against society, emphasizing the costs and limitations of compliance with externally imposed social and environmental standards. The creating shared value acknowledges trade-offs between short-term profitability and social or environmental goals, but focuses more on the opportunities for competitive advantage from building a social value proposition into corporate strategy.

Many organizations use the strategy of benchmarking to compete within their respective industries in OSR policy, implementation, and effectiveness. Benchmarking involves reviewing competitor OSR initiatives, as well as measuring and evaluating the impact that those policies have on society and the environment, and how customers perceive competitor OSR strategy. After a comprehensive study of competitor strategy and an internal policy review performed, a comparison can drawn and a strategy developed for competition with OSR initiatives.

\section{Managerial Social Responsibility}

Managerial Social Responsibility (MSR) is the responsibility of every manager for his/her actions. It is morally binding on everyone to act in such a way that the people immediately around them are not adversely affected. MSR is a commitment everyone has towards the society - contributing towards social, cultural and ecological causes.

MSR based on an individual's ethics. Instead of giving importance only to those areas where one has material interests, the individual supports issues for philanthropic reasons. MSR viewed as a tool for OSR.

MSR forms the base for OSR or Organizational Social Responsibility because if everyone in a business organization does his/her bit the bigger things automatically fall into place. The trends however show that big charitable organizations recorded high growth due to the social responsibility efforts of individuals and not corporate or the government. MSR may be slightly impractical, especially in the modern competitive world, where everyone works for self-interest, but it will succeed if we take decisions based on what will benefit a large number of people and respect everyone's fundamental rights.

\section{Corporate Social Responsibility}

For a business to take Corporate Social Responsibility (CSR) for its actions, that business must be fully accountable. Social accounting, a concept describing the communication of social and environmental effects of a company's economic actions to particular interest groups within society and to society, is thus an important element of CSR. Social accounting emphasizes the notion of corporate accountability.

Social accounting in this sense as an approach to reporting a firm's activities which stresses the need for the identification of socially relevant behavior, the determination of those to whom the company is accountable for its social performance and the development of appropriate measures and reporting techniques.

A number of reporting guidelines or standards developed 
to serve as frameworks for social accounting, auditing and reporting.

Many companies now produce externally audited annual reports that cover sustainable development and CSR issues, but the reports vary widely in format, style, and evaluation methodology even within the same industry.

An integrated report is includes environmental, social, economic performance alongside financial performance information and expected to provide users with a more holistic overview of a company as Figure 1.

\section{Organizational Social Responsibility Benefits}

Organizational Social Responsibility Benefits (OSRB) is the responsibility of every manager is as follows (http://en.wikipedia.org/wiki/Corporate_social_responsibilit y):

\subsection{Potential Business}

The scale and nature of the benefits of OSR for an organization can vary depending on the nature of the enterprise, and are difficult to quantify, though there is a large body of literature exhorting business to adopt measures beyond financial ones. However, businesses may not be looking at short-run financial returns when developing their OSR strategy.

The definition of OSR used within an organization can vary from the strict stakeholder impacts definition used by many OSR advocates and will often include charitable efforts and volunteering. OSR may base within:

a) The human resources,

b) The business development,

c) The public relations departments of an organization,

d) The given a separate unit reporting to the CEO or in some cases directly to the board. Some companies may implement OSR-type values without a clearly defined team or program.

\subsection{Human Resources}

A OSR program can be an aid to recruitment and retention, particularly within the competitive graduate student market. Potential recruits often ask about a firm's OSR policy during an interview, and having a comprehensive policy can give an advantage.

A growing consensus in the field of international training is that appropriate pedagogy of any program must begin with a thorough and suitable assessment of managers' strengths and weaknesses. Methods for individual assessment range from paper and pencil inventories, to elaborate role playing exercises, to behavioural assessment centres.

Organizations can improve the quality of managers by providing comprehensive training and development activities after assessment and selection. Considerable evidence suggests that investments in training produce beneficial individual and organizational outcomes.

International competence training and a sensible repatriation plan help buffer the stressors encountered abroad.

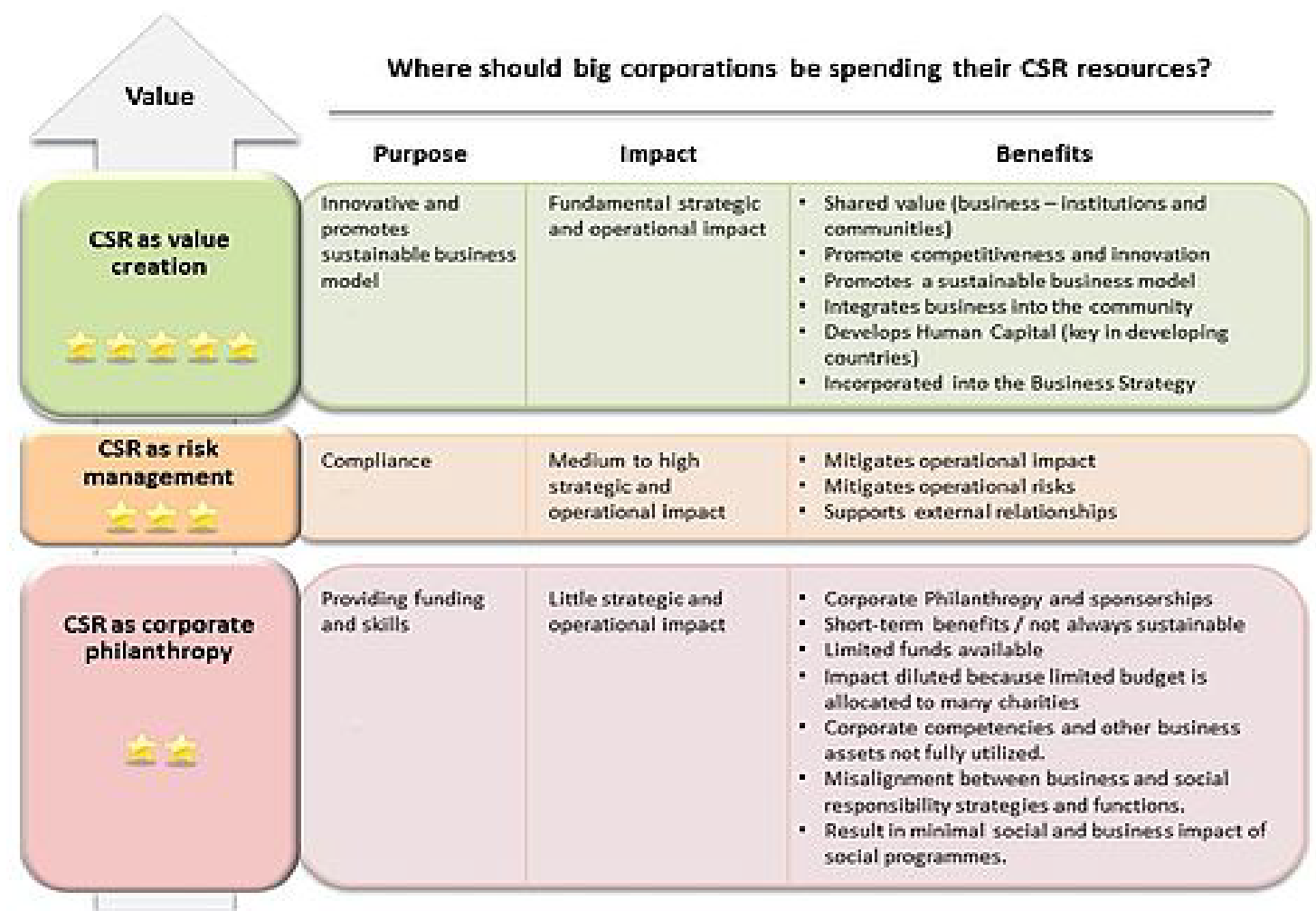

Figure 1. Corporate Social Responsibility

http://en.wikipedia.org/wiki/Corporate_social_responsibility 
The willingness and courage to undergo the profound personal transformation associated with an international assignment are essential for a healthy expatriate adjustment, even after the expatriate's return. International training can partly remedy cross-cultural insensitivity, but international competence involves more than a series of country statistics and cultural gimmicks learned in a short, pre-departure training session. Making executives aware that they will face different business and social customs is not sufficient, because awareness does not necessarily bring competence in the host culture.

Many organizations are becoming aware of the need to provide continued hands-on training rather than just pre-departure awareness training. In contrast to pre-departure training, post-arrival training gives global managers a chance to evaluate their stressors after they have encountered them. Documentary and interpersonal training methods have additive benefits in preparing managers for intercultural work assignments.

OSR can also help improve the perception of a company among its staff, particularly when staff can become involved through payroll giving, fundraising activities or community volunteering. OSR found to encourage customer orientation among frontline employees.

\subsection{Risk Management}

Managing risk is a central part of many corporate strategies. Reputations that take decades to build up can ruin in hours through incidents such as corruption scandals or environmental accidents. These can also draw unwanted attention from regulators, courts, governments and media. Building a genuine culture of 'doing the right thing' within a corporation can offset these risks.

\subsection{Brand Differentiation}

In crowded marketplaces, companies strive for a unique selling proposition that can separate them from the competition in the minds of consumers. OSR can play a role in building customer loyalty based on distinctive ethical values. Several major brands built on ethical values. Business service organizations can benefit too from building a reputation for integrity and best practice.

\subsection{License to Operate}

Corporations are keen to avoid interference in their business through taxation or regulations. By taking substantive voluntary steps, they can persuade governments and the wider public that they are taking issues such as health and safety, diversity, or the environment seriously as good corporate citizens with respect to labor standards and impacts on the environment.

\subsection{Criticisms and Concerns}

Critics of OSR as well as proponents debate a number of concerns related to it. These include OSR relationship to the fundamental purpose and nature of business and question- able motives for engaging in OSR, including concerns about insincerity and hypocrisy.

\subsection{Nature of Business}

An organization purpose is to maximize returns to its shareholders, and that since only people can have social responsibilities, corporations are only responsible to their shareholders and not to society as a whole. Although they accept that corporations should obey the laws of the countries within which they work, they assert that corporations have no other obligation to society. Some people perceive OSR as in congruent with the very nature and purpose of business, and indeed a hindrance to free trade. A wide variety of individuals and organizations operate in between these poles. For example, the leadership alliance asserts that the business of leadership be it corporate or otherwise is to change the world for the better.

Many religious and cultural traditions hold that the economy exists to serve human beings, so all economic entities have an obligation to society.

Moreover, many OSR proponents point out that OSR can significantly improve long-term corporate profitability because it reduces risks and inefficiencies while offering a host of potential benefits such as enhanced brand reputation and employee engagement.

\subsection{Motives}

Some critics believe that companies undertake OSR programs. Some corporations start OSR programs for the commercial benefit they enjoy through raising their reputation with the public or with government. Corporations, which exist solely to maximize profits, are unable to advance the interests of society as a whole.

Modern organizations can adopt various Human Recourses Management (HRM) practices to enhance employee satisfaction. The form and structure of an organization's human resources system can affect employee motivation levels in several ways.

Continuous training, employment security, performance appraisal and alternative compensation systems can motivate skilled employees to engage in effective discretionary decision making and behaviour in response to a variety of environmental contingencies. Recognizing the importance of HRM in achieving flexibility in an international context expands the types of research questions related to the role of HRM functions in organizational performance, such as selection of human resources, training, compensation and performance appraisal.

Organizations today are making abundant changes internally to cope with a highly turbulent external environment. With frequent reorganizing, downsizing, rightsizing, flattening the pyramid, teaming and outsourcing taking place, selection of human resources is also shaped by the fact that many people are experiencing major difficulties in their attempts to adapt to the uncertainties of career life.

Modern organizations try to adopt a pluralistic approach to 
career management that embraces different definitions of career success. Recognizing the diverse needs of employees enables the organization to reward and maintain diverse competencies in their workforces. Selecting the right person for the right place becomes a more sophisticated process since internal changes in organizations have a straight impact on traditional methods for selection of human resources.

Although many studies have reported a positive association between various human resources practices and objective and perceptual measures of selecting human resources for modern organizations, some authors have expressed concern that results may be biased because of methodological problems. Traditional methods for selection are mostly based on statistical techniques involving the analysis of test scores as well as empirical approaches based upon the intuition and experience of experts and their understanding of the job specifications and the capabilities of the candidates.

Modern approaches recognize that selection of human resources is a complex process that involves a significant amount of vagueness and subjectivity. Situational and individual-difference variables influence which category will dominate the decision maker's impression of the job candidate and exert the greatest influence on the hiring decision.

Innovative selection systems that seek to identify individuals with the ability to learn and adapt to new situations and markets can provide a firm with competitive advantage. International organizations can adopt various practices to enhance employee skills.

First, efforts can focus on improving the quality of the individuals hired, or on raising the skills and abilities of current employees, or on both. Employees can be hired via sophisticated selection procedures designed to screen out all but the very best potential employees. Indeed, research indicates that selectivity in staffing is positively related to firm performance.

Second, organizations can improve the quality of current employees by providing comprehensive training and development activities after selection.

What is important is the need to continuously review and update plans for career development and to acknowledge that individuals have varied and different perceptions. The more we understand people and their total environment, the more their needs are likely to be met.

The traditional psychological contract in which an employee entered a firm, worked hard, performed well, was loyal and committed, and thus received ever-greater rewards has started being replaced by a new contract based on continuous learning and identity change.

Employees are one of the most valuable resources and companies have to remain competitive. Modern organizations might achieve this by using organic human resources systems that promote the development of a human capital pool possessing a broad range of skills and that are able to engage in a wide variety of behaviour.

Training: In today's competitive global business environment, HRM functions are of significant importance for developing global managers. International training may be defined as any procedure intended to increase an individual's ability to cope and work in a foreign environment.

The importance of training in preparing an individual for an intercultural work assignment has become increasingly apparent. Managers are spending shorter periods in any single country and they often are moved from one location to another. Because their managers must often operate across borders in teams of internationally diverse units, many organizations express the need for managers who quickly adjust to multiple cultures and work well in multinational teams. This makes the challenge of international training increasingly difficult because conventional methods that rely on country specific knowledge often prove inadequate.

Critics concerned with corporate hypocrisy and insincerity generally suggest that better governmental and international regulation and enforcement, rather than voluntary measures, are necessary to ensure that companies behave in a socially responsible manner. A major area of necessary international regulation is the reduction of the capacity of corporations.

\subsection{Ethical Consumerism}

The rise in popularity of ethical consumerism over the last two decades can linked to the rise of OSR. As global population increases, so does the pressure on limited natural resources required to meet rising consumer demand.

Industrialization, in many developing countries, is booming because of both technology and globalization. Consumers are becoming more aware of the environmental and social implications of their day-to-day consumer decisions. Therefore, beginning to make purchasing decisions related to their environmental and ethical concerns.

\subsection{Globalization and Market Forces}

As corporations pursue growth through globalization, they have encountered new challenges that impose limits to their growth and potential profits. Government regulations, tariffs, environmental restrictions and varying standards of what constitutes labor exploitation are problems that can cost organizations millions of dollars. Some view ethical issues as simply a costly hindrance, while some companies use OSR methodologies as a strategic tactic to gain public support for their presence in global markets, helping them sustain a competitive advantage by using their social contributions to provide a subconscious level of advertising.

Global competition places a particular pressure on multinational corporations to examine not only their own labor practices, but also those of their entire supply chain, from a OSR perspective.

\subsection{Social awareness and Education}

The role among corporate stakeholders is to work collectively to pressure corporations that are changing. Shareholders and investors themselves, through socially responsible investing are exerting pressure on corporations to be- 
have responsibly. Non-governmental organizations are also taking an increasing role, leveraging the power of the media and the Internet to increase their scrutiny and collective activism around corporate behavior. Through education and dialogue, the development of community awareness in holding businesses responsible for their actions is growing. In recent years, the traditional conception of OSR challenged by the more community-conscious Creating Shared Value concept (CSV), and several companies are refining their collaboration with stakeholders accordingly.

\subsection{Ethics Training}

The rise of ethics training inside corporations, some of it required by government regulation, is another driver credited with changing the behavior and culture of corporations.

In training literature, two major forms of training employees in an organization have manifested. These are on the Job and off the Job training. Both forms have generated a lot of controversy on which should take precedence over the other. This in essence, means that there is yet to be a consensus among scholars on the various ways to meet the needs of the organization. Most experts however, agreed that the terms themselves suggest what they mean.

This is the method used to acquire specific skill while the individual is on the job. On the job training is required to improve the staff that had inadequate academic qualification for his job performance when he was employed specifically in a situation of acute manpower shortage.

This is also regarded as training within industry or training within organizational policy.

The definition also suggests that on -the- job method is a specific form of job instruction. It imparts only those skill needed by the worker to perform a particular job competently. This is why it is mostly done in plant.

However, it can be done outside the plant too. This specific form of training can both be formal and informal. Formal in the sense that, what is to be instructed is organized, manned or structured sequentially.

It was also discovered that failure to train employee leads to performance failure which invariably lead to the dent of the organizational reputation. Organisations should engage in identifying training needs as appropriate and also educate those trainers before conducting training programmes.

It was also discovered that mentoring and coaching of employee as a training techniques helps to increase acquisition and retainment of skill by employee as compare to other methods.

From the data analysed is clear that the training Programmes is well structured and planned as it leads to acquisition of new skill, knowledge and ability required for the actual performance on the job. It was also discovered that all employee of the organisation usually undergo training as soon as they become a full employee of the organisation.

From the data analysed, it was clear that growth and development of an organisation depends on the training that is giving to its employee likewise the reduction of the nature of hazards on the job.

It can therefore be said that for efficient performance of staff, different organizations should embark on training programmes and intensify their effort in training their workers while in service.

Increase in job performance will bring about increase in the rate of productivity, achievement of organizational goals and sound economy.

The aim of such training is to help employees make ethical decisions when the answers are unclear. Humans built with the capacity to cheat and manipulate, a view taken from, hence the need for learning normative values and rules in human behavior.

Increasingly, companies are becoming interested in processes that can add visibility to their OSR policies and activities. One method that is gaining increasing popularity is the use of well-grounded training programs, where OSR is a major issue, and business simulations can play a part in this.

\subsection{Laws and Regulation}

Another driver of OSR is the role of independent mediators, particularly the government, in ensuring that corporations prevented from harming the broader social well, including people and the environment. OSR critics argue that governments should set the agenda for social responsibility by the way of laws and regulation that will allow a business to conduct them responsibly.

The issues surrounding government regulation pose several problems. Regulation in itself is unable to cover every aspect in detail of a corporation's operations. This leads to burdensome legal processes bogged down in interpretations of the law and debatable grey areas.

\subsection{Crises and Their Consequences}

Often it takes a crisis to precipitate attention to OSR. Businesses nowadays are operating in a turbulent environment where organizations are searching for measures that will allow them to improve their performance and competitiveness.

Crises are generally regarded as disagreement regarding interests or ideas. In addition organizational crises is regarded as the discord that occurs when the goals, interests or values of different individuals or groups are incompatible with those of individuals or groups block or frustrate each others in an attempt to achieve their objectives. Crises are inevitable part of organizational life since the goals of different stakeholders such as managers and staff are often incompatible.

In addition, crises are an ever-present process in human relations. That is why various organizations have changed their approaches to enable them to manage their organizations effectively to avoid crises at all costs. Crises are a fact of life in any organizations as longer as people compete for jobs, resources, power, recognition and security. In addition, dealing with crises is a great challenge to management. 
Crises commonly arise when employees interact in organizations and compete for scarce resources. Employees in various organizations are organized into manageable groups in order to achieve common goal, therefore, the probability of crises to arise is very high.

Nowadays, most serious crises make headlines in the newspapers, which might affect the public image of the company. Crises have both negative and positive outcomes to the individual employees and the organization at large. There is no one source of crisess which occurs in organizations at all levels of management.

In social life, crises do occur but they are managed by family members, friends and relatives. The same case applies to organizations, when crises arise; it needs to be resolved by management for the sake of the organizational growth, survival and enhance performance. However, crises are rarely resolved easily, to a certain extend most crises are managed, as individuals work out differences.

Crises can occur within groups (intra-group crises) or among groups (inter-group crises). Therefore, the main aim of this study is to examine the sources of organizational crises and its effects on organizational performance.

It specifically tries to examine in detail, the causes, types, effects and recommend various strategies on how to resolve organizational crises to enhance organizational performance.

In any organization, there are many causes of crises; however crises within an individual usually arise when a person is uncertain about what task is expected to do, if not clearly defined by the supervisor or the person in charge. Furthermore, if the tasks of individuals working as a group are not clearly defined by the management they will lead to more crises. Crises between individuals may result from role-related pressures. Crises would arise between individuals and groups if the goals are not specified for individuals within a group.

Additionally, the following are other sources of crises within an organization namely: sharing of resources especially manpower, money materials, equipment and space required among departments. Resources are very scarce, people will always have to compete for them and the end result will lead to crises. Interdependent may also lead to crises, this usually occurs when two or more units depend upon one another to complete work of a product especially when a product passes through stages, one unit would complete work in good time, but other unit might delay the outcome of the whole product. The management might blame all units involved at each process which might lead to a crises. Incompatible personalities, which are psychological, might affect the employees not to get along with each other and this difficulty might lead to crises, which result from formal interactions with other employees.

Three basic types of crises are: task crises, interpersonal crises and procedural crises. Group members may disagree about facts or opinions from authorities.

The interpretation of evidence may be questioned. Disagreement about the substance of the discussion is called task crises. Task crises can be productive by improving the quality of decisions and critical thinking processes.

Another potential area for crises is the interpersonal relationships within the organization. The term interpersonal crises is used to indicate the disagreement that most people call a personality clash. This clash may take place in the form of antagonistic remarks that relate to the personal characteristics of a group member or disregard any organizational goals to antagonize a particular group member. Crises of this type are expressed through more subtle nonverbal behaviors. There may be icy stares or, at the other extreme, an avoidance of eye contact. Interpersonal crises may be inevitable and must be managed for optimal group co-existence.

Procedural crises exist when group members disagree about the procedures to be followed in accomplishing the group goal. New procedures may be formulated and a new agenda suggested. Even the group goal may be modified. Procedural crises, like task crises, may be productive

\subsection{Stakeholder Priorities}

Increasingly, corporations are motivated to become more socially responsible because their most important stakeholders expect them to understand and address the social and community issues that are relevant to them.

Understanding what causes are important to employees is usually the first priority because of the many interrelated business benefits that can be derived from increased employee engagement i.e. more loyalty, improved recruitment, increased retention, higher productivity, and so on.

Key external stakeholders include customers, consumers, and investor's particularly institutional investors, communities in the areas where the corporation operates its facilities, regulators, academics, and the media.

The stakeholder perspective of OSR as the inclusion of all groups or constituents rather than just shareholders in managerial decision-making is related to the organization's portfolio of socially responsible activities. This normative model implies that the OSR collaborations positively accepted when they are in the interests of stakeholders and may have no effect or be detrimental to the organization if they not directly related to stakeholder interests. The stakeholder perspective suffers from a wheel and spoke network metaphor that does not acknowledge the complexity of network interactions that can occur in cross sector partnerships. It also relegates communication to a maintenance function, similar to the exchange perspective.

\subsection{Disability and OSR}

In recent years, OSR is increasingly becoming a part of a large number of companies. It is becoming an important activity for businesses throughout the globe. OSR means that a company's business model should be socially responsible and environmentally sustainable. By socially responsible it means that the company's activities should benefit the society and by environmentally sustainable it means that the activities of the company should not harm the environment. 


\section{Result}

For the inclusion of disability aspect within OSR, firstly the whole system has to make less exclusive and hence more inclusive. Each individual is an important part of the world and must be acknowledged and accepted as such.

People with disabilities should not only allow being a part of the company as employees but also as clients/users, providers, stakeholders and investors.

There is a form of symbiotic relationship between Managerial Social Responsibility and Organizational Social Responsibility, Corporate Social Responsibility.

Social Responsibility practices, to successfully applied, need effective manager activity of the sort recognized and reciprocated by employees. Managers to be effective in workers management need Social Responsibility policies to work with and apply.

Employees respond to both the Managerial Social Responsibility practices and their manager leadership behavior.

The Organizational Social Responsibility judgment of Managerial Social Responsibility, directly related where positive to:

a) Higher levels of affective commitment;

b) Better aspects of job experience, managers are important in helping to create;

c) Transmit, impressions of the organization as a whole commitment and in making jobs satisfying by influencing how demanding the job is, how much autonomy the employee has in the job and the sense of achievement that comes from doing the job.

The manager influence it was clear that Organizational Social Responsibility practices, taken together, have similar effects if employees rate them highly.

In practice, there was an interactive and dynamic relationship between the Managerial Social Responsibility and the impact of Managerial Social Responsibility practices.

All research has its limitations and this study is no different. Although a significant proportion of Managerial Social Responsibility in each unit covered, the small number of respondents in each case limits analysis at the organization level.

However, the total number of achieved interviews is sufficient to draw some general conclusions with respect to these types of organizations with extensive Managerial Social Responsibility policies.

Most studies in the performance paradigm use the number of Managerial Social Responsibility practices in use as the input measure.

The action of organizations in trying to improve the Managerial Social Responsibility management behavior of their managers through behavioral selection, training, appraisal, career management and involvement did have a marked and measured effect on employee attitudes and behavior and on performance.

The example of organizations has clear implications for practitioners who wish to improve organizational performance as far as possible via workers management.
In particular, paying particular attention to managers as an occupational group with numerous responsibilities and often competing priorities is necessary. This can include building involvement and problem solving activities to allow access to decision makers and provide means for mutual support, better selection with greater emphasis given to leadership behaviors as well as technical skills and knowledge, access to further development, coaching and guidance and career management.

The relationship between Managerial Social Responsibility and the biggest variable explaining managers' own levels of affective commitment and job satisfaction is important. It also follows that since managers have a major role in bringing Managerial Social Responsibility policies to life, to quote a senior manager in one organization, the design of these policies should include consideration of how managers can apply them to be as user friendly as possible.

The other implication of the research is that it is Managerial Social Responsibility, which, through employee reciprocal behavior, influences organizational performance.

Managerial Social Responsibility is the combination of leadership behavior, and organizational climate, and conceptions of Social Responsibility need to take account of this wider agenda in both practice and theory.

\section{Conclusions}

The companies should develop an internal environment that encourages and supports disabled people. They should make accessibility easier by providing barrier free features. They should create and disseminate innovative frameworks and models, which address the unique difficulties of the disabled people so that they can actualize their capacities. Disabled should given preference for any work they can do within the limits of their abilities, whatever those limits may be.

There should be non-discrimination or diversity management awareness raising and training for employees in the companies that include disability treatment. They should include the disability factor in employment/HR indicators as age distribution, gender, contract type, professional categories and/or activity areas, rotation so that the situation of people with disabilities can be compared with that of other employees.

The companies should take into account the characteristics of people with disabilities when managing human resources as recruitment, selection, contracting and induction, promotion, training, prevention of risks at work.

Customer care staff should carried out by the companies aimed at guaranteeing appropriate treatment of people with disabilities. They should have a policy or directive aimed at considering or favoring suppliers and subcontractors that employ people with disabilities.

Thus, carrying out business practice, which includes disabled people, will help improve the company's reputation and image in an increasingly competitive environment. In 
this way, the company can not only maximize its economic performance but also improve its social performance.

Finally, disability is one of the factors that can contribute to diversity and diversity is a rising value within companies' management. However, disability often pushed behind in favor of other diversity criteria, thus disability needs to be specifically included within the OSR.

\section{REFERENCES}

[1] Akinyele, Samuel Taiwo (2007), The Impacts of Nigerian Training Programmes on Employees Performance, http://scialert.net/fulltext/?doi=rjbm.2007.11.19\&org=10

[2] Bethel, J. E. and Liebeskind, J. (1993). The effects of corporate ownership on corporate, Strategic Management Journal, 14

[3] Bolton, B and Thompson J. (2003), Entrepreneurs and Technique, London: Butterworth Heinemann

[4] Boselie, P., Dietz, G. and Boon, C. (2005). 'Commonalities and contradictions in research on human resource management and performance'. Human Resource Management Journal, 13: 3, 67-94

[5] Bowen, D. and Ostroff, C. (2004). 'Understanding HRM'. Academy of Management Review, 29: 203-221

[6] Boxall, P. and Purcell, J. (2003). Strategy and Human Resource Management,Basingstoke, UK: Palgrave

[7] Cameron Kim S, (1996), A study of organizational effectiveness and its predictors, Management science review

[8] Chandler Alfred Jr, (1992), Strategy and structure, Cambridge mass, M.I.T press

[9] Child, J. and Partridge, B. (1982). The Lost Managers: Supervisors in Industry and Society, Cambridge: Cambridge University Press

[10] Collis, D. J. and Montgomery, C. A. (1995), Competing on resources, Harvard Business Review, July-August, 73

[11] Cunningham, I. and Hyman, J. (1995).'Transforming the HRM vision into reality'. Employee Relations, 17: 8, 2-120

[12] E.E. Karsak (2004), Fuzzy multiple objective programming framework to prioritize design requirements in quality function deployment, Computers \& Industrial Engineering 47, pp. 149-163

[13] Eisenberger, R., Stinglhamber, F., Vandenberghe, C., Sucharski, I. and Rhoades, L. (2002).'Perceived supervisor support: contributions to perceived organizational support and employee retention'.Journal of Applied Psychology, 87

[14] Feghhi Farahmand, Nasser (2001), Executive Management Process, Islamic Azad University, Tabriz Branch, Iran, pp $9-413$

[15] Feghhi Farahmand, Nasser (2003), Permanent Management of Organization, First edition, Frouzesh Publication, Tabriz, Iran, pp 41-621

[16] Feghhi Farahmand, Nasser (2003), Strategic Structure of
Organization Management Process, Forth edition, Islamic Azad University, Tabriz Branch, Iran, pp 14-485

[17] Feghhi Farahmand, Nasser (2005), Strategic Management of Organization, First edition, Frouzesh Publication, Tabriz, Iran, pp 41-549

[18] Feghhi Farahmand, Nasser (2009), Organization Strategic Plan compilation, First edition, Frouzesh Publication, Tabriz, Iran, pp 21-284

[19] Feghhi farahmand, Nasser (2011), Active and Dynamic Management of Organization, Second edition, Frouzesh Publication, Tabriz, Iran, pp 17-496

[20] Feghhi Farahmand, Nasser (2011a), Technology Management of Organization, Second edition, Frouzesh Publication, Tabriz, Iran, pp 41-189

[21] Fenton O'Creevy, M. (2001). 'Employee involvement and the middle manager' Human Resource Management Journal, 11: $2,24-140$

[22] Fulmer, I., Gerhart, B. and Scott, K. (2003). 'Are the 100 best better? An empirical investigation of the relationship between being a "great place to work" and organization performance'. Personnel Psychology, 56: 865-993

[23] Gerhart, B. (2005).'Human resource systems', in C. Ostroff and T. Judge (eds), Perspectives on Organizational Fit, San Francisco: Jossey-Bass

[24] Griffin and Hauser, (1993), The voice of the customer, Marketing Science, no 12

[25] Grint, K. (1993). 'What's wrong with performance appraisal? A critique and suggestions'. Human Resource Management Journal, 3: 3, 41-77

[26] Guest, D. and Conway, N. (2004). Employee Well-being and the Psychological Contract: a Report for the CIPD,London: CIPD

[27] Guest, D., Michie, J., Conway, N. and Sheehan, M. (2003). 'Human resource management, British Journal of Industrial Relations, 41: 2, 195

[28] Hales, C. (2005). 'Rooted in supervision, branching into management'. Journal of Management Studies, 42: 3, 271-506

[29] Hannah, D. and Iverson, R. (2004). 'Employment relationships in context: implications for policy and practice', in J. Coyle-Shapiro, L. Shore, S. Taylor and L. Tetrick (eds), The Employment Relationship, Oxford: Oxford University Press, pp. $232-350$

[30] Harris, L. (2001). 'Rewarding employee performance'. International Journal of Human Resource Management, 12: 7, $882-1192$

[31] http://en.wikipedia.org/wiki/Corporate_social_responsibility

[32] http://en.wikipedia.org/wiki/Social_responsibility

[33] Hutchinson, S. and Purcell, J. (2003). Bringing Policies to Life: the Vital Role of Front Line Managers, London: CIPD

[34] Hutchinson, S. and Wood, S. (1995). Personnel and the Line: Developing a New Relationship, London: Institute of Personnel Management 
[35] J. Wang (1999), Fuzzy outranking approach to prioritize design requirements in quality function deployment, International Journal of Production Research 37 (4), pp. 899-916

[36] Johnson, M.D. Gustafsson, A. (2000), Improving customer satisfaction, Jossey Bass Press

[37] Kidd, J. and Smewing, C. (2001).'The role of supervisor in organizational '. European Journal of Work and Organizational Psychology, 10: 1, 35

[38] L.H. Chen and M.C. Weng (2006), An evaluation approach to engineering design in QFD processes using fuzzy goal programming models, European Journal of Operational Research 172 (1), pp. 230-248

[39] L.K. Chan, H.P. Kao, A. Ng and M.L. Wu (1999), Rating the importance of customer needs in quality function deployment by fuzzy

[40] Liden, R., Bauer, T. and Erdogan, B. (2004). 'The role of leader-member exchange in the dynamic relationship between employer and employee: The Employment Relationship: Examining Psychological and Contextual Perspectives, Oxford: Oxford University Press, pp. 226-252

[41] McConville, T. and Holden, L. (1999). 'The filling in the sandwich: managers in the health sector'. Personnel Review, 28: $5 / 6,306-424$

[42] McGovern, F., Gratton, L., Hope-Hailey(1997). 'Human resource management on the line?' Human Resource Management Journal, 7: 4, 12-49

[43] McKinley, W., Zhao, J. and Rust, K. G. (2000), A socio cognitive interpretation, Academy of Management Review, 25

[44] Morgan R, (1994), The Emergence of new organizational forms, London, no 27

[45] Nunally, J. (1978). Psychometric Theory, 2nd edn, New York: McGraw-Hill

[46] Ongori Henry (2009), Organisational Conflict and its Effects on Organisational Performance, http://scialert.net/fulltext/?doi=rjbm.2009.16.24\&org=10

[47] Ostroff, C. and Bowen, D. (2000). 'Moving HR to a higher level: HR practices and organizational effectiveness', in K. Klein and S. Kozlowski (eds), Multilevel Theory, Research and Methods in Organizations: Foundations, Extensions and New Directions, San Francisco: Jossey-Bass

[48] Polychroniou Panagiotis (2009), What about HRM? Advanced in management Journal, Department of Business Administration, University of Patras, University Campus, 26500, Patras, GREECE

[49] Purcell, J. and Kinnie, N. (2006). 'HRM performance', Oxford Handbook of Human Resource Management, Oxford: Oxford University Press

[50] Purcell, J., Kinnie, N., Hutchinson, S. (2004). Vision and Values: Culture and Values as Sources of Competitive Advantage, London: CIPD

[51] Purcell, J., Kinnie, N., Hutchinson's. (2003).Understanding the Workers and Performance Link: Unlocking the Black Box, London: CIPD

[52] Redman, T. and Snape, E. (2005). 'Unpacking commitment'. Journal of Management Studies, 42: 2, 301-328

[53] Seth, A., Song, K. P. and Pettit, R. R. (2002), Value creation and destruction, Strategic Management Journal, no 23

[54] Solvency Gavial, (1992), Handbook of industrial Engineering, John wily \&sons Inc

[55] Tekleab, A. and Taylor, M. (2003). 'Aren't there two parties in the employment relationship? Antecedents and consequences of organization-employee agreement on contract obligations and violations'. Journal of Organizational Behavior, 24: 385-608

[56] Thurley, K. and Wirdenius, H. (1973). Supervision: a Re-appraisal, London: Heinemann

[57] Truss, K. (2001). 'Complexities and controversies in linking HRM with organizational outcomes'. Journal of Management Studies, 38: 8, 928 